\title{
Cistitis enfisematosa. Caso clínico y revisión de literatura
}

\author{
Galiano Baena JF, Caballero Romeu JP, Galán Llopis JA, Leivar Tamayo A, Lobato Encinas JJ.
}

Servicio Urología. Hospital General Universitario Alicante.

Actas Urol Esp. 2008;32(9):948-950

\begin{abstract}
RESUMEN
CISTITIS ENFISEMATOSA. CASO CLÍNICO Y REVISIÓN DE LITERATURA

Presentamos el caso de una paciente con diagnóstico de cistitis enfisematosa. Realizamos la revisión bibliográfica de otros casos publicados de dicha patología. La cistitis enfisematosa es un cuadro infeccioso de rara presentación y más frecuente en pacientes mujeres diabéticas, caracterizado por la presencia de gas en la cavidad vesical e infiltración de las paredes vesicales, debido a la infección por gérmenes productores de $\mathrm{CO}_{2}$, principalmente gram (-). La peculiaridad de nuestro caso se debe a que la paciente no padecía diabetes, siendo mucho más frecuente que acontezca esta alteración en los pacientes que sí lo son.

Palabras clave: Cistitis. Diabetes Mellitus. Shock séptico.
\end{abstract}

\section{ABSTRACT \\ EMPHYSEMATOUS CISTITIS. CASE REPORT AND REVIEW OF LITERATURE}

We present the case of a patient with diagnostic of cystitis enphisematous. We carry out the bibliographical revision of other published cases of this pathology. The cystitis enphisematous is an infectious square of strange presentation and more frequent in patient diabetic women, characterized by the presence of gas in the bladder cavity and infiltration of the walls bladder, due to the infection for germs producing of $\mathrm{CO}_{2}$, mainly gram (-). The peculiarity of our case is due to that the patient didn't suffer diabetes, being much more frequent that this alteration happens in the patients that yes they are it.

Keywords: Cistitis. Diabetes Mellitus. Shock septic.

$\mathrm{L}^{\mathrm{a}}$ cistitis enfisematosa es una patología de baja incidencia. Cuando aparece, lo suele hacer en pacientes añosos, con patología de base, principalmente se asocia a la diabetes Mellitus. El diagnóstico se basa principalmente en los hallazgos radiológicos, ya que los datos clínicos son muy inespecíficos.

Exponemos un caso y la revisión bibliográfica a propósito del mismo ${ }^{1-10}$.

\section{CASO CLÍNICO}

Paciente mujer de 77 años que presenta como antecedentes personales ser alérgica a penicilina, hipertensión arterial, accidente isquémico transitorio, accidente cerebrovascular, demencia, osteoporosis y prótesis de cadera. No presenta diabetes Mellitus. La paciente había sufrido una caída con luxación de hombro y estaba siendo tratada con mórficos transdérmicos para el control álgico. Se encontraba ingresada en la unidad de sangrados digestivos por cuadro de hemorragia digestiva alta como consecuencia de esofagitis grado D demostrada en endoscopia.

A la exploración presentaba un dolor abdominal difuso, más acentuado en hipogastrio mitigado por el tratamiento analgésico. No presenta cuadro febril ni pneumaturia.

Analíticamente presentaba leucocitosis con desviación a la izquierda, aumento de niveles de PCR, y el resto de datos analíticos dentro de cifras normales. El sedimento urinario se encontraba alterado con piuria intensa, eritrocitos incontables campo y bacteriuria intensa. Se solicitó urocultivo cuyo resultado fue positivo para $E$. Coli.

En la radiología simple del aparato urinario no se determinan hallazgos patológicos. Debido a la persis- 
tencia del cuadro abdominal se solicitó TAC abdominopélvico, que informó de la existencia de gas en la luz de la vejiga e infiltrando las paredes de la misma, sin evidenciarse proceso inflamatorio o neoplásico que justifique fistulización enterovesical (Figs. 1 y 2). Con el diagnóstico de cistitis enfisematosa se procedió al cateterismo vesical obteniendo orina de aspecto purulento. Se instauró tratamiento antibiótico empírico de amplio espectro.

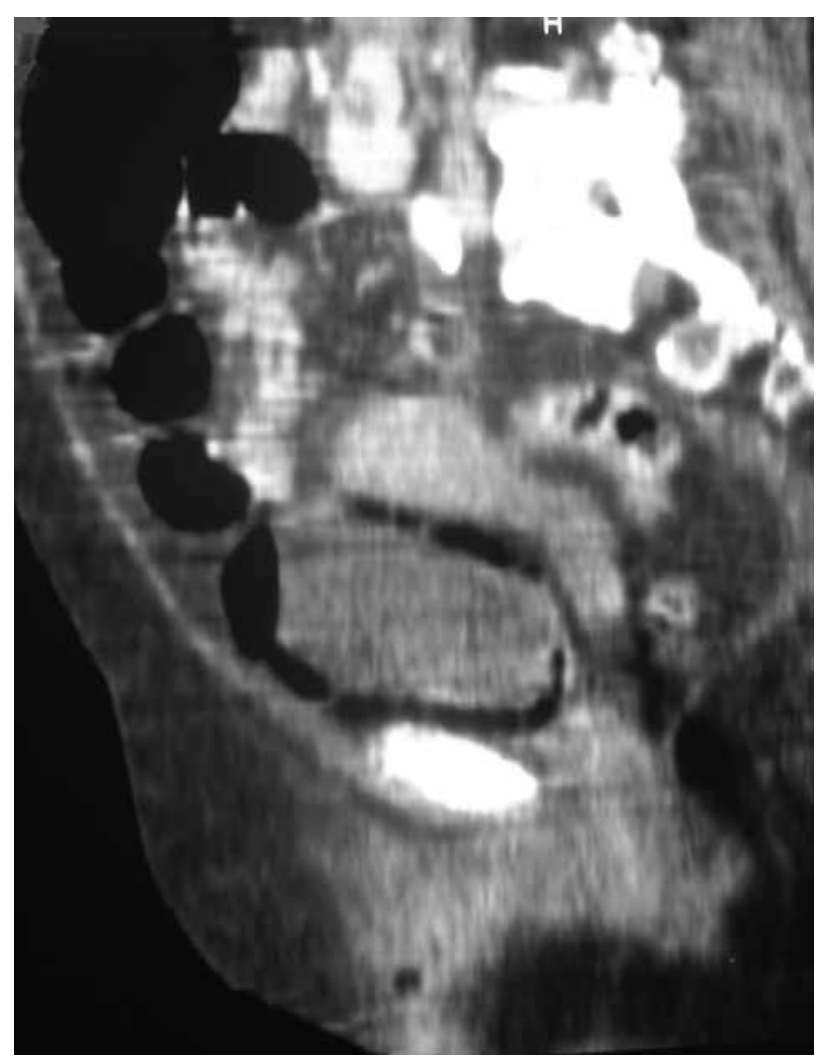

FIGURA 1

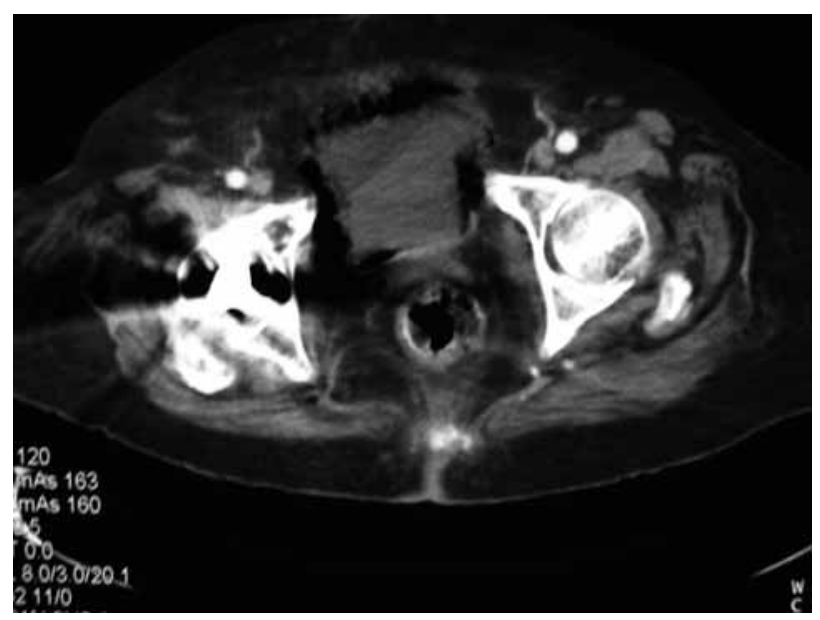

FIGURA 2
El cuadro empeoró en poco tiempo, con empeoramiento analítico: aumento de la cifra de leucocitos, alteraciones hidroelectrolíticas y de la función renal. La paciente hizo un cuadro de septicemia con fracaso multiorgánico y éxitus.

\section{DISCUSIÓN}

La cistitis enfisematosa es una rara entidad infecciosa que se caracteriza por la presencia de gas en la luz y paredes de la vejiga.

Los pacientes en los cuales ocurre dicho cuadro suelen ser mujeres añosas, con patología de base, principalmente diabetes Mellitus, que es la entidad más relacionada con la cistitis enfisematosa ${ }^{5}$. Pero existen otros factores que, aunque en menor medida, también pueden estar en relación, tales como las infecciones recurrentes del tracto urinario, los estados de inmunodepresión, vejigas neurógenas, divertículos vesicales, éstasis urinario y transplantados renales ${ }^{7}$.

La presentación clínica es inespecífica, desde sintomatología de infección del tracto urinario leve, hasta presentarse como peritonitis y shock séptico. En la mayoría de estos pacientes suelen aparecer síntomas de carácter irritativo propios de las infecciones urinarias y dolor abdominal. Un dato importante en la anamnesis es la presencia de pneumaturia. Este es un signo que no está presente en todos los casos ya que la cantidad de gas producida no es suficiente como para causarla, a no ser que se asocie éstasis urinaria ${ }^{6}$. En nuestra paciente no acontecía pneumaturia.

Los datos clínicos son insuficientes a la hora de obtener un diagnóstico en estos pacientes y son las imágenes radiológicas la clave para llegar al mismo. Una radiografía simple del aparato urinario puede demostrar la presencia de gas en el interior de la vejiga, pero es poco específica. En esta patología la utilidad de la ecografía es baja, aunque puede demostrarse un incremento en el grosor de las paredes vesicales. La resonancia magnética también es de poca utilidad, ya que la presencia de gas da lugar a la formación de falsas señales. Es la TAC la principal prueba diagnóstica, pudiendo apreciar la presencia de gas en la luz de la vejiga y en la mayoría de los casos, infiltración de las paredes vesicales por el gas. También es una técnica útil en la valoración de otras causas de la presencia de gas en la vejiga como la fístula enterovesical, pudiendo identificar la presencia de carcinoma o enfermedad inflamatoria en relación con esa posible fístula ${ }^{9}$. 
Ante la presencia de gas en vejiga debemos pensar en otros posibles diagnósticos como las fístulas vesicales (en relación con neoplasias, radioterapia, enfermedad inflamatoria intestinal, diverticulitis); traumas, procesos infecciosos, iatrogenia; debiendo hacer el diagnóstico diferencial con estas.

En el caso de la cistitis enfisematosa, la producción del gas se debe a la presencia de gérmenes que fermentan la glucosa presente en orina, generando dióxido de carbono. Al tratarse en la mayoría de los casos de pacientes diabéticos, las concentraciones de glucosa en orina están elevadas. Por otra parte, en pacientes no diabéticos, el sustrato bioquímico para la fermentación y la formación del gas puede ser la lactosa y albúmina ${ }^{1}$. El germen que con más frecuencia produce gas al infectar el aparato urinario es E. Coli, pero otros microorganismos pueden causar dicha patología, tales como Enterobacter aerogenes, Klebsiella pneaumoniae, Proteus mirabilis, Staphylococcus aureus, streptococos, Nocardia, Clostridium perfringens y Candida albicans ${ }^{1-3}$.

Una vez obtenido el diagnóstico, la cistitis enfisematosa requiere un tratamiento antibiótico agresivo, en principio de carácter empírico basado en los principales gérmenes relacionados, y a posteriori en función del resultado del urocultivo. Será preciso también colocar un catéter vesical para drenaje urinario.

Aunque la cistitis enfisematosa de trata de una patología grave y de evolución agresiva; con un diagnóstico temprano y un tratamiento adecuado el curso tiende a ser benigno, pero con una alta tasa de complicaciones tales como la extensión del proceso infeccioso hasta uréter y parénquima renal, perforación vesical, shock séptico y muerte. En nuestro caso, la evolución fue mala pese al tratamiento instaurado, con un empeoramiento clínico y analítico importante que acabó en shock séptico con fallo multiorgánico y éxitus en poco tiempo de evolución, pese al tratamiento instaurado.

\section{CONCLUSIÓN}

La cistitis enfisematosa es una rara entidad que aparece en muchos casos como hallazgo radiológico. Sin embargo es importante tener en cuenta esta patología y sospecharla sobre todo en aquellos pacientes que tienen factores de riesgo (diabetes principalmente), porque un diagnóstico temprano y la instauración del tratamiento igualmente precoz pueden ayudar a mejorar el pronostico de estos pacientes. Aún así, se trata de una enfermedad grave que puede conllevar a complicaciones severas.

\section{REFERENCIAS}

1. Moti Grupper, MD, Alexander Kravtsov, MD, Israel Potasman, MD. Emphysematous Cistitis. Illustrative case report and review of the literature. Medicine. 2007;86:47-53.

2. Ravi K Bobba, Edward L Arsura, Pawanjit S Sarna, Amar K Sawh. Emphysematous cystitis: an unusual disease of the genito-urinary system suspected on imaging. Ann Clin Microbiol Antimicrob. 2004; $3: 30$

3. Esther Nemati, Ramen Basra, Joyce Fernandes, Jeremy B. Levy. Emphysematous cystitis. Nephrol Dial Transplant 2005;20:652-653.

4. Anglada Curado FJ et al. Pneumocistos, una rara complicación infecciosa en diabéticos.Actas Urol Esp, 2001;25(1):67-68.

5. Velázquez Macias RF et al. Cistitis enfisematosa: asociación con diabetes mellitus y carcinoma gástrico. Informe de un caso. Medspain [revista en Internet], 2000 febrero [consultado febrero 2007], disponible en: http://www.medspain.com/ant n9_feb00/cistitis_enfis.htm.

6. Ho Kmt, Sole M. Pneumaturia due to gas-producing E.coli and urinary stasis. Br J Urol. 1994;73:588-589.

7. Akalin E, Hyde C, Schmitt G, Kaufman J, Hamburger RJ. Emphysematous cystitis and pyelitis in a diabetic renal transplant recipient. Tansplantation. 1996;62: 1024-1026.

8. Quint HJ, Drach GW, Rappaport WD, Hoffman CJ. Emphysematous cystitis: a review of the spectrum of disease. J Urol. 1992;147:134137.

9. Grayson, Capt, et al. Emphysematous infections of the abdominal and pelvis: a pictorial preview. Radiographics. 2002;22:543-561.

10. Anil A, Thomas, Brian R. Lane, Arun Z. Thomas, Erick M. Remer, Steven C. Campbell, Daniel A. Shoskes. Emphysematous cystitis: a review of 135 cases. BJU Internacional. 2007;100 (1):17-20.

Correspondencia autor: Dr. J.F. Galiano Baena.

Servicio de Urología. Hospital General Universitario de Alicante

Pintor Baeza, s/n - 03010 Alicante

Tel.: 965938000

E-mail autor: galianazo@hotmail.com

Información artículo: Nota clínica

Trabajo recibido: abril 2007

Trabajo aceptado: julio 2007 